\title{
SISTEMA REPRODUTIVO DE Sparattosperma leucanthum (VELL.) K. SCHUM. (BIGNONIACEAE) ${ }^{1}$
}

\author{
Leandro Pereira Polatto² e Valter Vieira Alves Júnior ${ }^{3}$
}

\begin{abstract}
RESUMO-Sparattosperma leucanthum (Vell.) K. Schum. (Bignoniaceae) é uma árvore polinizada por mamangavas, apesar de outros visitantes florais explorarem néctar ou pólen das flores sem exercerem benefício reprodutivo. Neste estudo, focalizaram-se aspectos do sistema de polinização, além de inferir se o espaçamento interplantas encontrado na área amostral e a quantidade de flores produzidas por árvore limitavam ou não a polinização por xenogamia em S. leucanthum. Assim, foram realizados testes reprodutivos, para obtenção da relação frutoflor, contagens do número de sementes por fruto e das árvores nos transectos amostrados e estimativa da quantidade de flores por árvores. S. leucanthum é autoincompatível e necessita dos visitantes florais para efetuar a polinização, pois se reproduz apenas por xenogamia. A razão fruto-flor obtida foi de 0,0054 , indicando alto custo energético, atribuído à baixa eficiência dos visitantes florais em promover a polinização. A distância interplantas foi relativamente menor que a distância máxima percorrida pelas mamangavas, enquanto as árvores produziram poucas flores por inflorescência e em intensidade moderada, auxiliando o processo de polinização por xenogamia, realizada pelas mamangavas. Entretanto, os frutos produziram grande quantidade de sementes, permitindo ampla proliferação de S. leucanthum na área estudada.
\end{abstract}

Palavras-chave: Visitantes florais, mamangavas e autoincompatibilidade.

\section{THE REPRODUCTIVE SYSTEM OF Sparattosperma leucanthum (VELL.) K. SCHUM. (BIGNONIACEAE)}

\begin{abstract}
Sparattosperma leucanthum (Vell.) K. Schum. (Bignoniaceae) is a tree pollinated by carpenter bees, although other floral visitors also explore the nectar or pollen of the flowers without exerting any reproductive benefit. This study focused on aspects of the pollination system and attempted to infer whether the interplant spacing found in the sampled area and the number of flowers produced by the tree limited pollination by crossbreeding with $\boldsymbol{S}$. leucanthum. Reproductive tests were carried out to obtain fruit-flower relationship, counting of the number of seeds per fruit and number of trees in the transects sampled and estimate of the number of flowers per tree. S. leucanthum is self-incompatible and needs floral visitors to carry out pollination, since it only reproduces by crossbreeding. The fruit-flower relationship obtained was 0.0054 , indicating a high energy cost attributed to the floral visitors' low efficiency in promoting pollination. The inter-plant distance was relatively shorter than the maximum distance traveled by the carpenter bees, while the trees produced few flowers per inflorescence and in moderate intensity, helping the pollination process by crossbreeding accomplished by the carpenter bees. However, the fruits produced a large number of seeds, allowing a wide proliferation of $\mathbf{S}$. leucanthum in the studied area.
\end{abstract}

Keywords: Floral visitors, carpenter bees and self-incompatibility.

\footnotetext{
${ }^{1}$ Recebido em 14.09.2007 e aceito para publicação em 06.03.2009.

${ }^{2}$ Programa de Pós-Graduação em Entomologia e Conservação da Biodiversidade da Universidade Federal da Grande Dourados (UFGD). E-mail: <lppolatto@gmail.com>.

${ }^{3}$ Faculdade de Ciências Biológicas e Ambientais da UFGD. E-mail: <valter_junior@ufgd.edu.br>.
} 


\section{INTRODUÇÃO}

Sparattosperma leucanthum (Vell.) K. Schum. (Bignoniaceae) é uma planta nativa do Brasil, típica da Mata Atlântica e da Floresta Semidecídua da Bacia do Paraná, ressaltando-se que apenas em Mato Grosso do Sul ela se tornou uma séria infestante de pastagens implantadas em área de antigas florestas (LORENZI, 2000a). Apresenta rápido crescimento, podendo ser empregada em plantios mistos para restauração da vegetação em áreas degradadas, pois se destaca por ser planta pioneira que preferem as formações secundárias como capoeiras e produzem grande quantidade de sementes (LORENZI, 2000b), favorecendo a sua rápida proliferação nessas áreas degradadas por processos antropogênicos. Essa espécie apresentou flores hermafroditas que se enquadram na síndrome de melitofilia, de acordo com a classificação de Faegri e van der Pijl (1979).

A maioria das angiospermas apresenta flores hermafroditas (SEAVEY e BAWA, 1986), aumentando as chances de polinização por autogamia ou geitonogamia (consideradas sistemas de polinização altamente endogâmicos). Entretanto, diversos mecanismos de autoincompatibilidade podem evitar ou reduzir o desenvolvimento de frutos altamente endogâmicos, como o bloqueio do desenvolvimento dos tubos polínicos, o abortamento de óvulos imediatamente após a fertilização (BERTIN, 1982) ou, mesmo, com o embrião e endosperma se desenvolvendo aparentemente normais e o abortamento do fruto devido ao desenvolvimento de poucos óvulos fertilizados com pólen xenogâmico (RICHARDS, 1997).

A geitonogamia pode também ter efeito negativo na capacidade reprodutiva masculina, reduzindo a transferência de pólen a outras plantas devido à sua perda durante ou entre visitas sucessivas nas flores de uma mesma planta (KLINKHAMER e DE JONG, 1993). Os problemas da geitonogamia são, provavelmente, mais severos em árvores de grande porte, porque produzem maior quantidade de flores (KLINKHAMER et al., 1997) e, consequentemente, os polinizadores reduzem o tempo e energia gasta no voo interplantas, forrageando as flores abundantes de uma única árvore (HEINRINCH, 1975). Em condições ótimas de transferência de pólen em plantas com reprodução predominantemente por xenogamia, a árvore é visitada por grande número de polinizadores, mas apenas pequeno número de flores é forrageado pelo polinizador em cada visitação (HARDER e THOMSON, 1989).

R. Árvore, Viçosa-MG, v.33, n.2, p.289-296, 2009

\section{R. Árvore, Viçosa-MG, v.33, n.2, p.289-296, 2009}

De acordo com Schuster et al. (1993), embasado em resultados de pesquisas, a produção limitada de sementes associada com a polinização pode ser o resultado da baixa atividade do polinizador, quando, então, limita o suprimento de pólen ao estigma (quantidade insuficiente de pólen transferido), ou a deficiência na qualidade dos grãos de pólen (e.g. excessiva proporção de pólen da mesma planta em espécies autoincompatíveis) ou, ainda, ambos os casos. Assim, a interação global na ecologia da polinização determina: 1) a proporção de polinização cruzada, autopolinização e intercruzamento biparental; 2) o número e origem espacial dos diferentes doadores de pólen que são efetivos contribuintes da progênie (tamanho efetivo da população e fluxo de genes através da dispersão de pólen); e 3) a eficácia de transmissão da diversidade genética adulta para progênie (a corte de semente) (HAMRICK et al., 1992). Ainda, de acordo com esses autores, os polinizadores fundamentalmente determinam a manutenção e enriquecimento da diversidade genética na população de plantas.

Dessa forma, teve-se por objetivos avaliar o sistema de polinização predominante de S. leucanthum, enfatizando a presença ou não de autocompatibilidade no processo de reprodução, e inferir sobre a necessidade ou não dos visitantes florais na polinização. Outro propósito foi avaliar se o espaçamento interplantas encontrado na área amostral e a quantidade de flores produzidas por árvore limitam ou não a reprodução por xenogamia nessa espécie.

\section{MATERIAL E MÉTODOS}

\section{1. Área de estudo}

O estudo foi conduzido em bordas de um fragmento de Floresta Secundária de aproximadamente 414,7 ha, pertencente à Sociedade de Melhoramentos e Colonização (SOMECO) e localizado lateralmente à estrada MS$395\left(22^{\circ} 15^{\prime} \mathrm{S}, 53^{\circ} 48^{\prime} \mathrm{W}\right)$, a cerca de $3 \mathrm{~km}$ do perímetro urbano do Município de Ivinhema, Mato Grosso do Sul, Brasil. Em meados da década de 1990, a área era constituída por vegetação nativa rarefeita mesclada com plantação de eucalipto, que por sua vez foi extraído comercialmente até o ano 2000, permanecendo apenas a vegetação nativa. Após a extração da madeira, a vegetação nativa se desenvolveu rapidamente, e durante o período do estudo em 2006 ela possuía estrutura lenhosa, apresentando-se em estádio médio de regeneração de acordo com os critérios propostos por Budowski (1965 e 1970). 
Segundo a classificação de Zavatini (1992), o clima da região se enquadra no tipo úmido a subúmido. Em 2006, a precipitação ocorrida no município foi equivalente a $1.234 \mathrm{~mL}$ e a temperatura média mensal foi de 23,7 $\pm 2,78$ ${ }^{\circ} \mathrm{C}$ (dados fornecidos pelo INMET).

\subsection{Sistema reprodutivo da planta}

Por meio do isolamento individualizado de várias flores de Sparattosperma leucanthum (Vell.) K. Schum. (Bignoniaceae) no início da antese (momento da abertura dos lobos da corola) e envolvidas em sacos de papel impermeável, impedindo seu contato com os visitantes florais, foram desenvolvidos os seguintes testes, em oito árvores adultas: 1) autopolinização espontânea, quando as flores não foram manipuladas após o ensacamento, para a verificação da formação ou não do fruto; 2) autopolinização manual, desenvolvida através da transferência manual do pólen pelo pesquisador ao estigma da própria flor; 3 ) geitonogamia, implicou transferência do pólen ao estigma de flores diferentes da mesma árvore; 4) xenogamia, houve a transferência do pólen ao estigma de flores situadas em árvores diferentes; e 5) apomixia, pela emasculação das flores. Com exceção da autopolinização espontânea, todos os demais testes reprodutivos tiveram suas flores emasculadas.

Outras flores foram marcadas sem passar por manuseio posterior, para ser verificada a produção de frutos em condições naturais. Visando minimizar possíveis influências nos resultados das polinizações e permitindo o desenvolvimento livre dos frutos (FREITAS e OLIVEIRA, 2002), os sacos de papel impermeável foram retirados no final da tarde do mesmo dia, considerando-se que em condições naturais a corola se desprende da flor nesse período.

Foram amostrados um total de 100 flores em cada teste reprodutivo subdivididos entre quatro e seis repetições, no período de fevereiro a maio de 2006 (período de média a alta intensidade de floração, de acordo com a classificação de Fournier (1974)), e tiveram seu desenvolvimento acompanhado diariamente até o desenvolvimento dos frutos e ocasionalmente até a sua maturação, culminando com a dispersão das sementes. As médias foram comparadas pelo teste quiquadrado, com nível de significância $\alpha=5 \%$.

Foram calculados os índices de autopolinização espontânea (ISA = percentual de frutificações formadas por autopolinização espontânea dividido pela porcentagem de frutos formados por autopolinização manual), de autoincompatibilidade (ISI = percentual de frutificações resultantes de autopolinização manual dividido pelo percentual de frutos oriundos de xenogamia) e a eficácia reprodutiva $(\mathrm{RE}=$ percentual de frutificações provenientes de polinização natural dividido pela porcentagem de frutificações formado por xenogamia), de acordo com a metodologia de Sobrevila e Arroyo (1982).

\subsection{Custo energético e eficiência na dispersão}

Foi avaliada a produção de flores e frutos por inflorescência, verificando-se a razão fruto-flor, o que permitiu analisar o investimento da espécie em termos do custo energético para a reprodução. Para essa análise foram amostradas casualmente e acompanhadas diariamente o desenvolvimento de 10 inflorescências em duas árvores de S. leucanthum, para a contagem das flores produzidas em cada uma delas. Paralelamente, foram amostradas, também casualmente, 97 inflorescências apresentando apenas frutos maduros em cinco árvores para a contagem dos frutos produzidos.

Foi avaliado, ainda, o número médio de sementes produzidas em cada fruto $(n=4)$ e as vantagens oferecidas em função do seu modo de dispersão pelo hábitat.

\subsection{Fatores limitantes a ocorrência da polinização xenogâmica natural}

Foram realizadas contagens da quantidade de árvores de $S$. leucanthum em quatro transectos que, somados, corresponderam a $1.250 \mathrm{~m}$ de comprimento por $8 \mathrm{~m}$ de largura. Através do espaçamento interplantas obtido, foi possível inferir se esse critério foi ou não um fator limitante da polinização por xenogamia, realizada pelos polinizadores efetivos, de acordo com relatos de Ghazoul et al. (1998) e Cunningham (2000).

Foi estimada a quantidade de flores em 10 árvores com altura superior a $6 \mathrm{~m}$, consideradas adultas, nos meses de março e abril de 2006 (período de alta intensidade de floração, segundo Fournier (1974)), pois, quanto menor a quantidade de flores por árvore, maior o fluxo de pólen entre elas, segundo Klinklamer et al. (1997).

Todos os valores médios citados no texto são seguidos por \pm erro-padrão.

R. Árvore, Viçosa-MG, v.33, n.2, p.289-296, 2009 


\section{RESULTADOS}

\subsection{Sistema reprodutivo da planta}

A maior taxa de polinização nas flores de Sparattosperma leucanthum (Vell.) K. Schum. (Bignoniaceae) ocorreu por xenogamia, e a maioria dos frutos se desenvolveu até a maturação. A quantidade dos frutos iniciados por polinização em geitonogamia e autopolinização manual foi estatisticamente menor que o número de frutos iniciados em xenogamia $\left(\chi^{2}=5,88\right.$; g.1.=1; $\mathrm{P}=0,0015$ e $\chi^{2}=7,25 ;$ g. $1 .=1 ;$ e $\mathrm{P}=0,007$, respectivamente), sendo todos (100\%) abortados, ainda, na fenofase de frutos imaturos. Não foi constatada produção de frutos nos testes de autopolinização espontânea e apomixia. A polinização natural ocorreu em $9 \%$ das flores, mas apenas $1 \%$ atingiu a fenofase de fruto maduro (Tabela 1 ).

Tabela 1 - Resultados das polinizações controladas desenvolvidas em Sparattosperma leucanthum (Vell.) K. Schum. (Bigononiaceae). Em cada teste foram amostradas 100 flores, subdivididas entre quatro e seis repetições (RP), durante o período de fevereiro a maio de 2006

Table 1 - Results of the developed controlled pollinations in Sparattosperma leucanthum (Vell.) K. Schum. (Bigononiaceae). For each test they had been showed 100 flowers subdivided between 4 and 6 repetitions $(R P)$ during the period of February and May of 2006

\begin{tabular}{lccc}
\hline $\begin{array}{l}\text { Testes } \\
\text { reprodutivos }\end{array}$ & RP & F1 $(\% \pm \mathrm{EP})^{1}$ & Fr $(\% \pm \mathrm{EP})^{2}$ \\
\hline Xenogamia & 5 & $48 \pm 7,07 \mathrm{a}$ & $35 \pm 11,07 \mathrm{a}$ \\
Geitonogamia & 5 & $27 \pm 4,95 \mathrm{~b}$ & $0 \mathrm{~b}$ \\
Autopolinização & 5 & $25 \pm 9,54 \mathrm{~b}$ & $0 \mathrm{~b}$ \\
manual & & $0 \mathrm{c}$ & $0 \mathrm{~b}$ \\
Autopolinização & 4 & $0 \mathrm{c}$ & $0 \mathrm{~b}$ \\
espontânea & & $9 \pm 5,93 \mathrm{~d}$ & $1 \pm 0,93 \mathrm{~b}$ \\
$\begin{array}{l}\text { Apomixia } \\
\text { Polinização }\end{array}$ & 6 & 0,52 & 0 \\
natural & & 0 & 0 \\
ISI & & 0,19 & 0,029 \\
ISA & & & \\
RE $^{5}$ & & &
\end{tabular}

Médias seguidas pelas mesmas letras nas colunas não diferem significativamente pelo teste do qui-quadrado $(\mathrm{P}<0,05)$; averages followed for the same letters in the columns do not differ significantly for the test of the quisquare $(\mathrm{P}<0,05) .1 \mathrm{Fl}=$ flores polinizadas (porcentagem \pm erro-padrão). $2 \mathrm{Fr}=$ frutos maduros (porcentagem \pm erro-padrão). 3 ISI (índice de autoincompatibilidade) $=$ porcentual de frutificações resultante de autopolinização manual dividido pelo porcentual de frutos oriundos de xenogamia. 4ISA (índice de autopolinização espontânea)= porcentual de frutificações formado por autopolinização espontânea dividido pelo porcentual de frutos formados por autopolinização manual. $5 \mathrm{RE}$ (eficácia reprodutiva)= porcentual de frutificações provenientes de polinização natural dividido pelo porcentual de frutificações formadas por xenogamia.
$\mathrm{Na}$ análise dos índices reprodutivos, constatou-se que a planta é autocompatível ao considerar-se o processo de polinização, mas apresenta autoincompatibilidade tardia (os frutos não atingem a fase de maturação), uma vez que, de acordo com Oliveira e Gibbs (2000), quando o ISI for menor que 0,25 , a planta será considerada autoincompatível (Tabela 1).

O índice de autopolinização espontânea apresentou valor zero (Tabela 1), definindo a necessidade de animais polinizadores para realizar a polinização nessa espécie vegetal, apesar de a flor não possuir mecanismos clássicos que impeçam a autopolinização espontânea. A eficácia reprodutiva também se apresentou muito baixa (Tabela 1), indicando eficiência reduzida de polinização pelas mamangavas, apesar do grande número de visitações (in loco).

Quando se investigou a taxa de aborto de flores até o período propício à visualização do fruto, geralmente a partir do $12^{\circ}$. dia após a deposição do pólen na antera, constatou-se a ocorrência de aborto de todas as flores nos testes de apomixia e autopolinização espontânea até o $7^{\circ}$ dia após a deposição do pólen. Inversamente, nos testes de xenogamia, geitonogamia e autopolinização manual ocorreu taxa de aborto constante ao longo dos 12 dias iniciais. A polinização natural ficou em situação intermediária entre os dois grupos, conforme se verifica na Figura 1. A partir desse período foi possível visualizar os frutos com tamanho de aproximadamente $2 \mathrm{~cm}$ de comprimento e a ocorrência de aborto em menor intensidade, prosseguindo por até dois meses. Não foi constatado aborto de frutos maduros.

\subsection{Custo energético e eficiência na dispersão}

A razão fruto-flor foi de $0,0054(0,5 \pm 0,1$ fruto por inflorescência versus $99 \pm 10,5$ flores por inflorescência), indicando alto custo energético para a planta no processo reprodutivo. Esse resultado, estatisticamente semelhante ao encontrado no teste de polinização natural quando considerada a fase de fruto maduro $\left(\chi^{2}=0,14 ; \mathrm{P}>0,05\right)$ (Tabela 1), confirma a baixa taxa de frutificação em condições naturais.

As visitações realizadas pelos visitantes coletores de pólen limitaram a disponibilidade deste. Geralmente, a ocorrência de cinco visitas por flor foi suficiente para a não visualização a olho nu do pólen nas anteras. 
Assim, após o período das $10 \mathrm{~h}$ as visitações realizadas pelos polinizadores efetivos às flores de $S$. leucanthum tornaram-se pouco eficientes, pois a quantidade de grãos de pólen disponível para aderir ao corpo desses animais a ser transportado ao estigma das flores de outras plantas dessa espécie tornou-se muito pequena. Ainda, apenas pequena parte das visitações nas flores de $S$. leucanthum foi realizada pelas mamangavas durante o período de estudo, consideradas os polinizadores efetivos (in loco). Neste estudo, também foram observadas constantes visitações geitonogâmicas pelas mamangavas quando as árvores de $S$. leucanthum se encontravam esparsamente dispersas. Entretanto, nos agrupamentos densos a taxa de visitação xenogâmica foi intensa na maioria das visitas realizadas pelas mamangavas.

Mesmo com baixa produção de frutos em condições naturais, a espécie encontra-se bem estabelecida na região estudada. Assim, a dispersão anemófila de sementes e a sua germinação, mesmo com baixa produção de frutos, são suficientes para permitir a manutenção da espécie ou, até mesmo, a sua proliferação em casos especiais, como em hábitats degradados, o que se deve à grande quantidade de sementes produzidas por fruto, com média de 405,5 $\pm 22,8$ sementes.

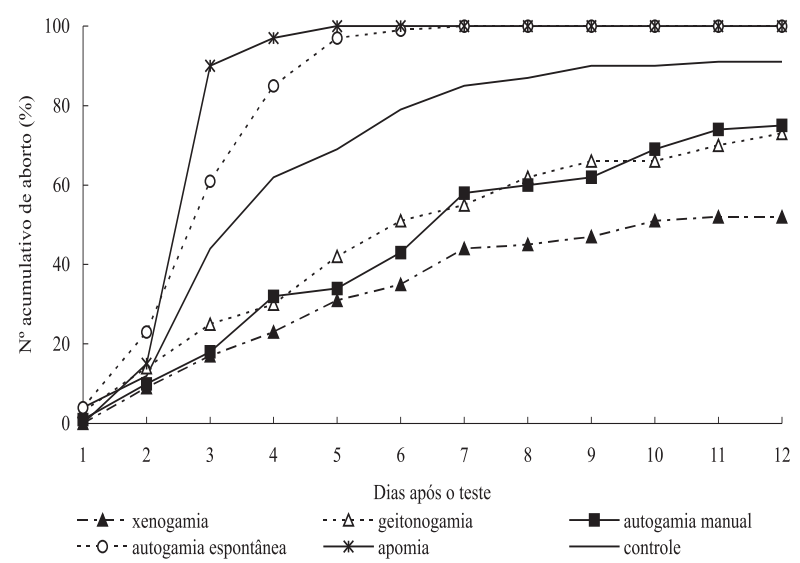

Figura 1 - Porcentagem cumulativa de abortos de flores nos testes reprodutivos realizados em Sparattosperma leucanthum (Vell.) K. Schum. (Bigoniaceae), como consequência do insucesso na polinização.

Figure 1 - Cumulative percentage of abortions of flowers in the carried through reproductive tests in Sparattosperma leucanthum (Vell.) K. Schum. (Bigoniaceae) as consequence of failure in the polinização.

\subsection{Fatores limitantes a ocorrência da polinização xenogâmica natural}

Neste estudo foram encontradas 76 árvores de S. leucanthum dentro dos quatro transectos de 1.250 $\mathrm{m}$ de comprimento por $8 \mathrm{~m}$ de largura. Segundo Roubik (1989), as mamangavas Bombus sp são capazes de forragear a distâncias de até $1.200 \mathrm{~m}$ do ninho. Assim, essas abelhas teriam condições de forragear diversas árvores quando seus ninhos se localizam próximos a elas, efetuando acidentalmente a polinização por xenogamia e de acordo com Gusson et al. (2006), mantendo o coeficiente de endogamia populacional a uma taxa baixa.

O favorecimento ao forrageamento em mais de uma árvore de $S$. leucanthum pelas mamangavas estaria associado também à baixa produção de flores por inflorescência (cerca de duas ou três flores) e por moderada intensidade de florescimento individual $(x=207 \pm 45$ flores por árvore adulta; amplitude variando entre 50 e 500 flores por árvore).

\section{DISCUSSÃO}

Os resultados dos testes de reprodução indicam que a fenofase de fruto maduro foi atingida apenas pelo processo de xenogamia, que pode ser explicado pela não fecundação ou aborto de todos os frutos imaturos nos demais testes reprodutivos. Para a presença de um fruto maduro originado por polinização natural, sugere-se que os óvulos que os originaram tenham sido fecundados provavelmente por pólen xenogâmico.

Com relação aos índices de reprodução, parece não ocorrer o sistema de autoincompatibilidade clássico que, segundo Freitas e Oliveira (2002), impede a germinação do pólen, o crescimento do tubo polínico e até mesmo a sua penetração no óvulo. Segundo Gibbs et al. (1999), diversos estudos sobre os mecanismos de incompatibilidade em plantas tropicais encontraram número elevado de espécies que apresentam sistema de incompatibilidade tardia. Portanto, o aborto de frutos altamente endogâmicos pode ser devido à presença desse sistema, impedindo a maturação desses frutos. Nessa situação, sugere-se o desenvolvimento de poucos óvulos fertilizados por pólen altamente endogâmico (SEAVEY e BAWA, 1986) ou, então, a ocorrência de abortamento do fruto devido ao desenvolvimento de poucos óvulos fertilizados com pólen xenogâmico, mesmo com o desenvolvimento aparentemente normal do embrião e do endosperma (RICHARDS, 1997).

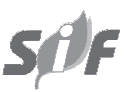

R. Árvore, Viçosa-MG, v.33, n.2, p.289-296, 2009 
Para a eficácia reprodutiva baixa, os mecanismos encontrados na maioria das espécies vegetais com reprodução realizada predominantemente por xenogamia são: a expressão do sexo dióico, a hercogamia (separação espacial das estruturas reprodutivas masculinas e femininas em uma mesma flor), a dicogamia (separação fenológica da maturação dos órgãos masculinos e femininos) e a heterostilia (ocorrência, nas flores de estames com filetes curtos e estiletes longos) (PYKE, 1978; BAKER, 1983). Contudo, nenhum desses mecanismos foi observado na flor de Sparattosperma leucanthum, sugerindo que existam outros fatores não identificados, impedindo a ocorrência de autopolinização espontânea.

Perante a baixa taxa de polinização e frutificação ocorrida naturalmente, são levantadas duas hipóteses. A primeira leva em conta a insuficiente quantidade de pólen transportado ao estigma da flor (SCHUSTER et al., 1993), visto que nos testes reprodutivos foi transferida manualmente ao estigma grande quantidade de pólen. A mesma hipótese pode ser aplicada para a ausência de produção de frutos no teste de autopolinização natural, ocorrendo provavelmente pouca deposição de pólen no estigma das flores na ausência de visitantes florais.

A primeira hipótese corrobora Schuster et al. (1993), que verificando o aumento da quantidade de frutos maduros em função do aumento do número de grãos de pólen por estigma, concluíram que houve limitação quantitativa do suprimento de pólen às flores de Asphodelus aestivus Brot. (Liliaceae). Esses autores também encontraram correlação positiva entre a quantidade de pólen e o número de sementes (fertilizações) por flor. Então, o aborto seletivo de frutos pode ser devido à limitação dos recursos (STEPHENSON e WINSON, 1986).

A segunda hipótese, também de acordo com Schuster et al. (1993), envolveria a baixa qualidade do pólen transportado ao estigma, devido a altas taxas de visitas geitonogâmicas realizadas pelas mamangavas. Freitas e Oliveira (2002) encontraram proporção de frutos maduros originados por polinização natural em Copaifera langsdorffii (Leguminosae) igual à deste estudo. Atribuíram que a baixa produção de frutos poderia estar relacionada com a alta taxa de polinização geitonogâmica.

Por ser planta pioneira e apresentar dispersão anemófila de suas sementes, o sistema de proliferação torna-se muito eficiente por não necessitar de animais para sua realização, como já ficou demonstrado por Ganeshaiah et al. (1998), quando mostraram que a perturbação antrópica de florestas de Biligiri Ranganswamy Hills, na Índia, levou à redução acentuada de populações vegetais, cujas sementes dependiam da dispersão por animais, quando comparados com àquelas dispersadas passivamente ou pelo vento.

A distância e os mecanismos de dependência da densidade que agem na polinização e produção de sementes foram descritos em várias espécies, em uma variedade de ambientes tropicais com plantas isoladas ou populações fragmentadas, mostrando ocorrer fecundidade reduzida devido ao declínio da eficiência de polinização (WILCOCK e NEILAND, 2002). Entretanto, ainda pouco se sabe como a reprodução das plantas sofre impactos em relação a sua distribuição populacional (GHAZOUL e SHAANKER, 2004).

Dessa forma, os resultados deste estudo indicam que o sucesso reprodutivo natural da população de $S$. leucanthum seria altamente dependente da quantidade e qualidade de pólen, devendo ser obrigatoriamente xenogâmicoe, em grande quantidade, depositado no estigma das flores. Adicionalmente, futuros estudos tornam-se necessários para estimar os índices de germinação em campo, o que possibilitaria estimar a taxa de estabelecimento da planta no ambiente (OLIVEIRA et al., 2006).

\section{AGRADECIMENTOS}

Ao Professor Doutor Alan Sciamarelli, da Faculdade de Ciências Biológicas e Ambientais da Universidade Federal da Grande Dourados, pela identificação da espécie vegetal estudada; à Sociedade de Melhoramentos e Colonização (SOMECO), pela permissão do desenvolvimento do estudo na área $\mathrm{e}$ fornecimento dos dados métricos desta; ao Instituto Nacional de Meteorologia (INMET), pelo fornecimento dos dados ambientais de 2006 (precipitação e temperatura); e ao Conselho Nacional de Desenvolvimento Científico e Tecnológico (CNPq), pela bolsa concedida ao primeiro autor.

\section{REFERÊNCIAS}

BAKER, H. G. An outline of the history of anthecology, or pollination biology. In: REAL, L. (Ed.). Pollination biology. Orlando: Academic Press, 1983. p.7-28 
BERTIN, R. I. Paternity and fruit production in trumpet creeper (Campsis radicans). The American Naturalist, v.119, n.5, p.694-709, 1982.

BUDOWSKI, G. Distribuiton of tropical american forest species in a light of sucessional process. Turrialba, v.15, n.1, p.40-42, 1965.

BUDOWSKI, G. The distinction between old secondary and climax species in tropical central american lowland forests. Tropical Ecology, v.11, n.1, p.44-48, 1970.

CUNNINGHAM, S. A. Depressed pollination in habitat fragments causes low fruit set.

Proceedings of the Royal Society of London. Series B: Biological Sciences, v.267, p.1149-1152, 2000.

FAEGRI, K.; van der PIJL, L. The principles of pollination ecology. 3.ed. London: Perganon Press, 1979.

FOURNIER, L. Un método cuantitativo para la medición de características fenológicas en árboles. Turrialba, v.24, p.422-423, 1974.

FREITAS, C. V.; OLIVEIRA, P. E. Biologia reprodutiva de Copaifera langsdorffii Desf. (Leguminosae, Caesalpinioideae). Revista Brasileira de Botânica, v.25, n.3, p.311-321, 2002.

GANESHAIAH, K. N. et al. Extraction of nontimber forest products in the forests of Biligiri Rangan Hills, India. 5. Influence of dispersal mode on species response to anthropogenic pressures. Economic Botany, v.52, p.316-319, 1998.

GHAZOUL, J.; LISTON, K. A.; BOYLE, T. J. B. Disturbance-induced density-dependent seed set in Shorea siamensis (Dipterocarpaceae), a tropical forest tree. Journal of Ecology, v.86, p.462-473, 1998.

GHAZOUL, J.; SHAANKER, R. U. Sex in space: pollination among spatially isolated plants. Biotropica, v.36, n.2, p.128-130, 2004.

GIBBS, P. E.; OLIVEIRA, P. E.; BIANCHI, M. B. Postzygotic control of selfing in Hymenaea stigonocarpa (Leguminosae- Caesalpinioideae), a bat-pollinated tree of the Brazilian cerrados.

International Journal of Plant Sciences, v.160, p.72-78, 1999.
GUSSON, E.; SEBBENN, A. M.; KAGEYAMA, P. Y. Sistema de reprodução em populações de Eschweilera ovata (Cambess.) Miers. Revista Árvore, v.30, n.4, p.491-502, 2006.

HAMRICK, J. L.; GODT, M. J. W.; SHERMANBROYLES, S. L. Factors influencing levels of genetic diversity in woody plant species. New Forests, v.6, n.1, p.95-124, 1992.

HARDER, L. D.; THOMSON, J. D. Evolutionary options for maximizing pollen dispersal of animalpollinated plants. American Naturalist, v.133, p.323-344, 1989.

HEINRINCH, B. Thermoregulation in bumblebees II. Energetics of warm-up and free flight. Journal of Comparative Physiology, v.96, n.1, p.155-166, 1975.

KLINKHAMER, P. G. L.; DE JONG, T. J. Attractiveness to pollinators: a plant's dilemma. Oikos, v.66, p.180-184, 1993.

KLINKHAMER, P. G. L.; DE JONG, T. J.; METZ, H. Sex and size in cosexual plants. Trends in Ecology and Evolution, v.12, n.7, p.260-265, 1997.

LORENZI, H. Plantas daninhas do Brasil: terrestres, aquáticas, parasitas e tóxicas. 3.ed. Nova Odessa: Instituto Plantarum, 2000a.

LORENZI, H. Árvores brasileiras: manual de identificação e cultivo de plantas arbóreas nativas do Brasil. 3.ed. Nova Odessa: Instituto Plantarum, 2000b. v.1.

OLIVEIRA, P. E.; GIBBS, P. E. Reprodutive biology of wood plants in cerrado community of Central Brazil. Flora, v.195, p.311-329, 2000.

OLIVEIRA, A. K. M.; SCHLEDER, E. D.; FAVERO, S. Caracterização morfológica, viabilidade e vigor de sementes de Tabebuia aurea (Silva Manso) Benth. \& Hook. f. ex. S. Moore. Revista Árvore, v.30, n.1, p.25-32, 2006.

PYKE, G. H. Optimal foraging in bumblebees and coevolution with their plants. Oecologia, v.36, n.3, p.281-293, 1978.

R. Árvore, Viçosa-MG, v.33, n.2, p.289-296, 2009 
RICHARDS, A. J. Plant breeding systems. London: George Allen \& Unwin, 1997. 529p.

ROUBIK, D. W. Ecology and natural history of tropical bees. New York: Cambridge University Press, 1989. 404p.

SEAVEY, S. R.; BAWA, K. S. Late-acting selfincompatibility in Angiosperms. Botanical Review, v.52, v.2, p.195-219, 1986.

SCHUSTER, A.; NOY-MEIR, I.; HEYN, C. C.; DAFNI, A. Pollination-dependent female reproductive success in a self-compatible outcrosser, Asphodelus aestivus Brot. New Phytologist, v.123, p.165-174, 1993.
SOBREVILA, C.; ARROYO, M. T. K. Breeding systems in a montane tropical cloud forest in Venezuela. Plant Systematics and Evolution, v.140, n.1, p.19-37, 1982.

STEPHENSON, A. G.; WINSON, J. A. Lotus corniculatus regulates offspring quality through selective fruit abortion. Evolution, v.40, p.453-458, 1986.

WILCOCK, C.; NEILAND, R. Pollination failure in plants: Why it happens and when it matters.

Trends in Plant Science, v.7, n.270-277, 2002.

ZAVATINI, J. A. Dinâmica climática no Mato Grosso do Sul. Geografia. Rio Claro: IGCE/ UNESP, 1992. v.17. p.65-91. 